\title{
Intensive Care Unit Management of Pneumonia
}

\author{
THOMAS J. NOLAN AND DAVID G. MCCORMACK
}

\section{Severe Community-Acquired Pneumonia}

\section{Definition}

A small subset of patients with community-acquired pneumonia (CAP) require intensive care unit (ICU) admission for mechanical ventilation, hemodynamic support, or monitoring. The term severe CAP evolved after a number of prospective studies reported a series of reasonably consistent characteristics seen in this particular population of patients. This classification is worthwhile since the bacteriology, management, and prognosis of CAP patients requiring ICU admission are distinct from those of other CAP syndromes. A practical definition of severe CAP based on clinical and radiographic criteria was formulated by an American Thoracic Society consensus conference (Niederman et al., 1993). In general, severe CAP requires ICU admission and is characterized by at least one of the criteria listed in Table 1. Although this definition is helpful, it may describe a sizeable proportion of hospitalized patients not requiring ICU management. Ewig et al. (1998) have proposed a more stringent definition for severe CAP in which two of three minor criteria (systolic blood pressure $<90$ $\mathrm{mm} \mathrm{Hg}$, multilobar involvement, $\mathrm{PaO}_{2} / \mathrm{FIO}_{2}<250$ )

\section{THOMAS J. NOLAN AND DAVID G. Mc CORMACK} London Health Sciences Centre, Victoria Campus, London, Ontario NGA 4G5, Canada.

Community-Acquired Pneumonia, edited by Marrie. Kluwer Academic/Plenum Publishers, New York, 2001. and one of two major criteria (mechanical ventilation, septic shock) must be present. The sensitivity and specificity of this revised definition for predicting pneumonia requiring ICU admission are $78 \%$ and $94 \%$, respectively.

\section{Pathogens of Severe Community- Acquired Pneumonia}

\section{Diagnostic Yield}

Discussion of etiologic microorganisms in severe CAP is tempered by the fact that, despite rigorous investigations, diagnosis remains elusive in as many as half of all cases. Rello et al. (1993) studied 58 consecutive patients admitted to an ICU for CAP and established the cause in $60 \%$. Diagnosis was confirmed by either positive blood or pleural fluid cultures, serology, or protected brush specimens obtained at the time of bronchoscopy. Torres et al. (1991) evaluated 92 patients in a Spanish ICU and determined exact etiology in $52 \%$ of cases. In an earlier series, Pachon et al. (1990) were able to diagnose the cause of severe CAP in $42 \%$ of 67 patients. Both Pachon and Torres used transthoracic needle aspiration in addition to more conventional techniques to establish a bacteriological diagnosis.

Despite the availability of invasive diagnostictests in most ICUs, several factors conspire against a specific diagnosis in this setting. Thus, many patients receive antibiotic therapy prior to admission to the ICU. This not only reduces the likelihood of a positive culture result but also predisposes individ- 
TABLE 1. Criteria for Severe Pneumonia ${ }^{a}$

\begin{tabular}{|c|c|c|}
\hline & $\begin{array}{l}\text { Sensitivity } \\
(\%)\end{array}$ & $\begin{array}{l}\text { Specificity } \\
(\%)^{b}\end{array}$ \\
\hline \multicolumn{3}{|l|}{ Respiratory failure } \\
\hline Respiratory rate $>3(0 / \mathrm{min}$ & 64 & 57 \\
\hline $\mathrm{PaO}_{2} / \mathrm{FIO}_{2}<250$ & 64 & 65 \\
\hline Mechanical ventilation required & 58 & 100 \\
\hline \multicolumn{3}{|l|}{ Shock } \\
\hline $\begin{array}{l}\text { Systolic BP }<90 \text { or diastolic } \\
<60 \mathrm{~mm} \mathrm{Hg}\end{array}$ & 12 & 99 \\
\hline $\begin{array}{l}\text { Vasopressors required for }>4 \\
\text { hours }\end{array}$ & 38 & 100 \\
\hline $\begin{array}{l}\text { Acute renal failure requiring } \\
\text { hemodialysis }\end{array}$ & 30 & 96 \\
\hline \multicolumn{3}{|l|}{ Radiographic } \\
\hline Bilateral infiltrates & 41 & 86 \\
\hline Multilobar infiltrates & 52 & 89 \\
\hline $\begin{array}{l}\text { Increase in infiltrate by } 50 \% \text { at } \\
48 \text { hours }\end{array}$ & 28 & 92 \\
\hline
\end{tabular}

"Niederman et al., 1993.

'Ewig et al., 1998. uals to upper airway colonization from potentially pathogenic bacteria. Furthermore, certain groups of patients are more likely to require ICU management of their pneumonia, such as the elderly, and those with concomitant illness are also more likely to have misleading upper airway colonization with potentially pathogenic bacteria (Valenti et al., 1978). Despite this uncertainty, knowledge of common pathogens of severe CAP is crucial as initial and appropriate empiric therapy is likely to be associated with improved outcome (Pachon et al., 1990; Moine et al., 1994).

\section{Pathogens}

Common pathogens responsible for severe CAP are shown in Figure 1. As in other CAP syndromes, Streptococcus pneumoniae remains the most frequently identified etiologic pathogen. Legionella spp. and aerobic gram-negative bacteria are identified more frequently in these patients than in other less critically ill subjects with CAP.

\section{Streptococcus pneumoniae}

A common feature of virtually all studies examining etiologic diagnoses in severe CAP is the

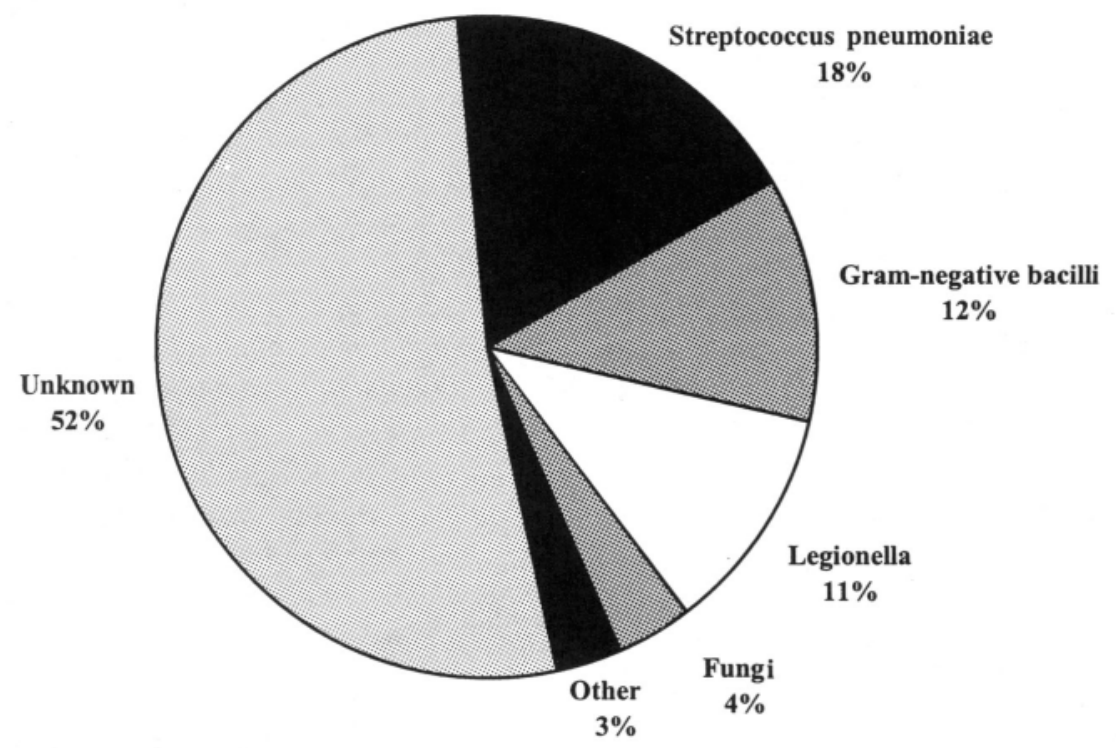

FIGURE 1. Pathogens in severe community-acquired pneumonia. Other includes viruses, Mycobacterium tuberculosis, and Pneumocystis carinii. Adapted from Pachon et al., 1990. 
prevalence of Pneumococcus. The most common organism in six recent prospective studies involving 435 patients from four different countries was $S$. pneumoniae, isolated in $15 \%$ to $46 \%$ of patients requiring ICU management. Pneumococcus remains the most frequently identified pathogen in all age groups requiring ICU admission for CAP.

\section{Legionella pneumophila}

Legionella has been found to be a particularly common cause for admission to the ICU, second only to S. pneumoniae (Table 2). The frequency of Legionella in severe CAP is conspicuous relative to its incidence in the community, suggesting that Legionella infection results in a more severe form of pneumonia than do other pathogens. Despite this apparent virulence, Legionella does not appear to be an independent risk factor for death following admission to an ICU, with mortality rates of $25 \%$ to $30 \%$, similar to the overall rates for severe CAP.

\section{Pseudomonas aeruginosa}

While pseudomonal species are common pathogens in nosocomial pneumonia, their role in severe CAP is not clear. In 1993, consensus guidelines for the treatment of severe CAP advocated the use of antibiotics with anti-pseudomonal activity-a third-generation cephalosporin such as ceftazidime, ciprofloxacin, or imipenem. However, three prospective trials involving 235 patients failed to identify $P$. aeruginosa as a potential pathogen in patients admitted to the ICU with severe CAP. When it has been reported, its prevalence is generally very low $(3 \%-5 \%)$, and its presence is typically associated with underlying structural lung disease such as bronchiectasis or neoplasia (Rello et al., 1996; Leroy et al., 1995; Torres et al., 1991) or recent discharge from hospital (Hirani \& Macfarlane, 1997).

\section{Mycoplasma pneumoniae}

Mycoplasma is a common causative agent in CAP in young adults but progression to respiratory failure is rare. In patients requiring hospitalization, Marrie (1993) found that approximately $10 \%$ went on to require assisted ventilation but none of these patients died from their infection. Indeed, Torres et al. (1991) found that while M. pneumoniae was the third most commonly identified pathogen in their series of severe CAP, no mortality was associated with this infection.

\section{Enterobacteriaceae}

While these pathogens are unusual in patients with CAP outside the ICU, they collectively represent an important cause of severe CAP. Together Klebsiella pneumoniae, Escherichia coli, and Enterobacter spp. are generally reported as the third most common cause of CAP identified in the ICU. Upper airway colonization with gram-negative rods is an important step in the pathogenesis of this disease and therefore the elderly, debilitated, and chronically ill are at particular risk.

\section{Viruses}

Despite the frequency of acute respiratory infections due to viruses, there is a paucity of information on the role of these pathogens in severe CAP. Retrospective studies rarely obtain comprehensive serological data and few prospective studies

TABLE 2. Legionella and Severe Community-Acquired Pneumonia

\begin{tabular}{llcccc}
\hline Author & \multicolumn{1}{c}{ Country } & $\begin{array}{c}\text { Number } \\
\text { of patients }\end{array}$ & \% Legionella & $\begin{array}{c}\text { Legionella } \\
\text { mortality (\%) }\end{array}$ & $\begin{array}{c}\text { Study } \\
\text { mortality (\%) }\end{array}$ \\
\hline Rello et al., 1996 & Spain & 95 & 3 & 66 & 40 \\
Moine et al., 1994 & France & 132 & 3 & 25 & 24 \\
Rello et al., 1993 & Spain & 58 & 23 & 25 & 22 \\
Pachon et al., 1990 & Spain & 67 & 22 & 0 & 21 \\
Sorenson et al., 1989 & Sweden & 36 & 8 & 33 & 24 \\
Woodhead et al., 1985 & United Kingdom & 50 & 30 & 33 & 54 \\
\hline
\end{tabular}


are able to examine all relevant viruses. Moine et al. (1994) identified seven patients with either varicellazoster, influenza, or parainfluenza pneumonia, representing $5 \%$ of their patients with severe CAP. Cytomegalovirus was identified by Sorensen et al. (1989) in two patients out of 36 with CAP requiring $1 \mathrm{CU}$ admission. Diagnosis usually requires paired serology with convalescent liters; consequently most patients who die with viral pneumonia do not have a confirmed diagnosis.

Viral infections, particularly those due to influenza A and B, play a unique role in severe CAP due to their propensity to result in a secondary infection, often from Staphylococcus aureus. Hirani and Macfarlane (1997) found that the majority of severe CAP pneumonias due to $S$. aureus were associated with recent infection with influenza A or $B$ virus.

Hantavirus has been characterized only recently but has a significant propensity to cause acute respiratory failure. Endemic to the southwestern United States, hantavirus pulmonary syndrome has also been described in additional geographic areas in North and South America. Although Hantavirus is a relatively rare cause of CAP, it appears that virtually all individuals with this infection require ICU management, and the case fatality rate is close to $50 \%$ (Levy \& Simpson, 1994).

\section{Mycobacterium tuberculosis}

Tuberculosis infection should always be considered in a differential diagnosis of severe CAP. Although it is relatively uncommon in most Western cohorts (Torres et al.,1991; Sorensen et al.,1989; Woodhead et al., 1985), the importance of M. tuberculosis as an infectious disease worldwide should not be underestimated. In a Singapore ICU, the incidence of tuberculosis as a cause of severe CAP was 16\% (Tan et al., 1998) and in Saudi Arabia 8\% (Dahmash \& Chowdury, 1994).

\section{Diagnosis}

An array of diagnostic procedures exist for the elucidation of specific etiologic pathogens in severe CAP. However, the cost, potential complications, and questionable clinical utility of these procedures have resulted in considerable controversy in this subject.

In trials in which pathogenic etiology was exhaustively sought, the proportion of undefined pathogens remained frustratingly high. Hirani and Macfarlane (1997), for example, failed to identify a causative agent in about one third of all patients studied despite a combination of cultures, convalescent serology, and antigen testing. Moreover, the inability to diagnose etiology has not yet been found to be an independent predictor for mortality in multivariate analysis (Leroy et al., 1996). Nevertheless, there are compelling arguments in favor of establishing an etiologic diagnosis. For example, fewer patients would require prolonged courses of broad-spectrum antibiotic therapy, thereby decreasing the development of resistant organisms. Furthermore, current empiric antibiotic treatment strategies are based on previous regional experience which can come only from prior etiologic investigations.

Invasive diagnostic techniques are warranted in patients with severe CAP who fail to respond to empiric therapy. This may be defined as the absence of a clinical response (persistence of fever, leukocytosis, increasing infiltrates) 48 to 72 hours after initiation of treatment. In these instances, the possibility of antimicrobial resistance, superinfection, or M. tuberculosis, fungal, or viral pneumonia should be considered, and fiberoptic bronchoscopy with bronchoalveolar lavage and protected specimen brushing is warranted. Open lung biopsy is rarely, if ever, used to diagnose CAP but may be indicated when diagnoses other than pneumonia are being considered.

\section{Treatment}

The treatment of severe CAP requires management of acute respiratory failure, initiation of empiric antimicrobial therapy, and identification of complications frequently seen in the ICU.

\section{Management of Acute Respiratory Failure}

Respiratory failure may be defined as a significant impairment of the respiratory system's capacity to perform gas exchange. This is manifest clinically by arterial hypoxemia and/or hypercapnia. 
Respiratory failure is defined as a $\mathrm{PaO}_{2}$ less than 60 $\mathrm{mm} \mathrm{Hg}$ while breathing room air and/or a $\mathrm{PaCO}_{2}$ greater than $45 \mathrm{~mm} \mathrm{Hg}$. Patients with severe CAP will present with type 1 or oxygenation failure due to ventilation-perfusion ( $\left.\dot{\mathrm{V}}_{\mathrm{A}} / \mathrm{Q}\right)$ imbalance and shunting. Lampron et al. (1985) demonstrated that the most common pattern of $\dot{\mathrm{V}}_{\mathrm{A}} / \dot{\mathrm{Q}}$ mismatch in patients with bacterial pneumonia severe enough to require mechanical ventilation was a combination of intrapulmonary shunt and increased perfusion to lung units with low $\dot{\mathrm{V}}_{\mathrm{A}} / \dot{\mathrm{Q}}$ ratios. This impairment of gas exchange represents a potential threat to life and must be rapidly identified and aggressively treated.

There are three components in the initial management of acute respiratory failure secondary to pneumonia: airway management, ventilation, and oxygenation.

\section{Airway Management}

Although upper airway obstruction is generally not the primary cause of acute respiratory failure in pneumonia, all patients should initially be evaluated for upper airway patency. Secondary obstruction can occur due to loss of oropharyngeal tone or poor clearance of secretions in moribund patients and necessitates immediate endotracheal intubation. Additional indications for intubation are listed in Table 3.

\section{Ventilation}

Alveolar Ventilation. The typical blood gases of a patient with severe CAP demonstrate hypoxemia associated with a normal or slightly reduced $\mathrm{PaCO}_{2}$. In fact, significant disorders of ventilation are unusual unless concomitant illness is present or respiratory arrest is incipient. Alveolar ventilation $\left(\dot{\mathrm{V}}_{\mathrm{A}}\right)$ is the volume of gas entering the lungs each minute that is available for gas exchange. The relationship between $\dot{\mathrm{V}}_{\mathrm{A}}$ and $\mathrm{PaCO}_{2}$ can be expressed by the following equation:

$$
\mathrm{PCO}_{2} \propto \frac{\dot{\mathrm{V}} \mathrm{CO}_{2}}{\dot{\mathrm{V}}_{\mathrm{A}}}
$$

where $\dot{\mathrm{V}} \mathrm{CO}_{2}$ is the rate of carbon dioxide production. This is of particular relevance to patients with

\section{TABLE 3. Indications for Endotracheal Intubation and Assisted Ventilation}

Refractory hypoxemia

Ventilatory failure - severe respiratory acidosis $(\mathrm{pH}<7.25)^{a}$

Impending respiratory failure - rising $\mathrm{PaCO}_{2}$, respiratory muscle fatigue $^{a}$

Airway control-impaired secretion clearance, loss of protective reflexes

"May be improved with noninvasive ventilation, thereby obviating the need for endotracheal intubation.

depression of central respiratory drive, abnormal neuromuscular function, or airflow obstruction who develop pneumonia and a consequent increase in metabolic activity and $\mathrm{V}_{\mathrm{CO}_{2}}$, and are then unable to increase $\dot{\mathrm{V}}_{\mathrm{A}}$.

Mechanical Ventilation. Acute ventilatory failure has traditionally been treated with intubation and mechanical ventilation. The primary goal of mechanical ventilation in this setting is to provide assistance when the work of breathing is excessive and unsustainable or when insufficient VA results in unacceptable acidosis.

Noninvasive Ventilation. The usefulness of noninvasive mechanical ventilation (NIV) has been established for patients with acute respiratory failure due to exacerbations of chronic obstructive pulmonary disease (Keenan et al., 1997). More recently, NIV has been shown to be as effective as conventional ventilation in improving gas exchange in patients with hypoxemic respiratory failure (Antonelli et al., 1998). NIV is an attractive alternative to conventional forms of ventilation; it eliminates the need for endotracheal intubation, reduces the length of stay in the ICU, and improves outcome. A trial of NIV in acute respiratory failure secondary to pneumonia should be considered in centers with experience in this technique and where continuous monitoring is available.

\section{Oxygenation}

Hypoxemia is the hallmark of acute respiratory failure due to pneumonia and must be corrected. The goal of therapy is to ensure adequate delivery of oxygen to tissues $\left(\mathrm{Do}_{2}\right)$. The determinants of $\mathrm{Do}_{2}$ include concentration of hemoglobin $(\mathrm{Hb})$ and car- 
diac output (CO) as well as oxygen saturation $\left(\mathrm{SaO}_{2}\right)$ :

$$
\mathrm{Do}_{2}=13.4 \times \mathrm{Hb} \times \frac{\mathrm{SaO}_{2}}{100} \times \mathrm{CO}
$$

Therefore, in addition to increasing $\mathrm{SaO}_{2}, \mathrm{DO}_{2}$ can also be improved by increasing cardiac output and correcting anemia. If necessary, patients should be placed on $100 \%$ oxygen administered by a nonrebreather face mask and the unaffected lung should be positioned dependently to improve $\dot{V} / \mathrm{Q}$ matching. An inspired concentration of oxygen of only about $60 \%$ is attainable by face mask and often patients with high degrees of $\dot{V} / \mathrm{Q}$ mismatch (or shunts) are refractory to this therapy. In these instances, endotracheal intubation and mechanical ventilation is required. Intubation permits the delivery of a greater concentration of oxygen, and mechanical ventilation reduces the work of breathing, thereby diminishing oxygen consumption.

\section{Antibiotics}

\section{Empiric Therapy}

The emergence of multidrug-resistant strains of bacteria, regional variation in common pathogens (and patterns of resistance), newer antibiotics, and the difficulty in establishing an etiologic diagnosis makes the subject of empiric therapy somewhat contentious. Nevertheless, early empiric antimicrobial therapy is important in the treatment of severe CAP. In fact, failure to provide effective initial antibiotic treatment has been identified as an independent prognostic factor for poor outcome in severe CAP (Torres et al., 1991; Leroy et al., 1996).

Several guidelines for the empiric treatment of severe CAP have been published in the last decade and are summarized in Table 4. There is common agreement on the need to provide effective coverage of $S$. pneumoniae, aerobic gram-negative rods, and Legionella with appropriate rationalization of treatment when pathogenic organisms are identified.

In 1993, the British Thoracic Society suggested the use of erythromycin combined with a second- or third-generation cephalosporin or, alternatively, ampicillin with flucloxacillin and erythromycin (Finch et al., 1993). In the same year the American Thoracic Society recommended a regimen
TABLE 4. Treatment Guidelines

\begin{tabular}{|c|c|}
\hline & Treatment \\
\hline $\begin{array}{l}\text { Infectious Disease Society } \\
\text { of America (Bartlett et } \\
\text { al., 1998) }\end{array}$ & $\begin{array}{l}\text { Erythromycin, azithromycin, or } \\
\text { a fluoroquinolone }{ }^{a} \text { plus } \\
\text { cefotaxime, ceftriaxone, or a } \\
\beta \text {-lactam- } \beta \text {-lactam } \\
\text { inhibitor }^{b}\end{array}$ \\
\hline $\begin{array}{l}\text { American Thoracic Society } \\
\text { (Niederman et al., 1993) }\end{array}$ & $\begin{array}{l}\text { Macrolide plus third- } \\
\text { generation cephalosporin } \\
\text { with anti-Pseudomonas } \\
\text { activity }\end{array}$ \\
\hline $\begin{array}{l}\text { British Thoracic Society } \\
\text { (Finch et al., 1993) }\end{array}$ & $\begin{array}{l}\text { Erythromycin plus second- or } \\
\text { third-generation } \\
\text { cephalosporin or ampicillin } \\
\text { plus flucloxacillin }\end{array}$ \\
\hline
\end{tabular}

"Levofloxacin, sparlfoxacin, trovafloxacin, or grepafloxacin.

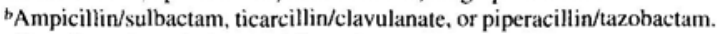
'Ciprofloxacin or imipenem/cilastatin.

consisting of a macrolide combined with a thirdgeneration cephalosporin with anti-pseudomonal activity such as ceftazidime (Neiderman et al., 1993). Imipenem/cilastatin or ciprofloxacin may be used in lieu of the cephalosporin.

More recently, the Infectious Disease Society of America advocated the use of erythromycin, azithromycin, or a fluoroquinolone combined with a third-generation cephalosporin or a $\beta$-lactam$\beta$-lactamase inhibitor (Bartlett et al., 1998). These guidelines are the first to incorporate the newer fluoroquinolones such as levofloxacin, sparfloxacin, or moxifloxacin, all of which have enhanced activity against $S$. pneumoniae (compared to firstgeneration fluoroquinolones) and appear to be effective against atypical pathogens as well (File et al., 1997).

\section{Specific Pathogens}

Streptococcus pneumoniae. The most commonly identified pathogen in severe CAP, $S$. pneumoniae has historically been sensitive to penicillins and cephalosporins. The emergence of drugresistant S. pneumoniae (DRSP) calls into question the adequacy of current guidelines advocating the use of second or third generation cephalosporins. Although in vitro resistance has been associated with poor outcome in patients with DRSP meningitis treated with penicillin, the same does not 
appear to apply to patients with pneumonia. Observational studies show no difference in outcome if pneumonia due to DRSP is treated with penicillins or third-generation cephalosporins (Pallares et al., 1995; Plouffe et al., 1996). Therefore, current guidelines for empiric treatment of severe CAP are adequate unless high levels of resistance (MIC $>4$ $\mu \mathrm{mg} / \mathrm{mL}$ ) are suspected on the basis of regional prevalence. In such cases, vancomycin, imipenem, or a newer fluoroquinolone should be considered.

Legionella pneumophila. There is little debate regarding the need to provide empiric coverage for Legionella in cases of severe CAP requiring ICU admission. Distinguishing Legionella pneumonia from other pneumonias can be difficult if not impossible on clinical grounds. Furthermore, $L e$ gionella's propensity for causing severe disease and the knowledge that delay in appropriate therapy significantly increases mortality (Stout \& Yu, 1997) argue strongly in favor of empiric coverage. Erythromycin ( $1 \mathrm{~g} \mathrm{IV}$ every 6 hours) is the drug of choice and the addition of rifampin is warranted for confirmed cases. Both azithromycin and the newer fluoroquinolones have significant in vitro and in vivo activity against Legionella and may become acceptable therapy in the future.

\section{Nutrition}

Critical illness of any kind precipitates a metabolic environment of increased energy expenditure and catabolism. Therefore, patients with severe CAP who may require mechanical ventilation for more than 24 hours should be provided with adequate nutrition. Enteral nutrition has several advantages over total parenteral nutrition (TPN). In patients with critical illness, it appears to support gut barrier function, reduce septic complications, and improve outcome compared with TPN (Minard \& Kudsk, 1998). It is also less costly and obviates the potential for TPN-related catheter sepsis or liver disease. For these reasons, whenever possible, enteral feedings should be initiated within 24 hours of admission to the ICU. Parenteral nutritional support should be considered for patients with a nonfunctioning gut or those intolerant of enteral feeding such that the period of fasting does not exceed 5 days.

\section{Complications of Severe Community- Acquired Pneumonia}

\section{Acute Respiratory Distress Syndrome}

\section{Definition}

A relatively common complication of severe CAP is progression to acute respiratory distress syndrome (ARDS). This is a process of nonhydrostatic pulmonary edema and hypoxemia and is associated with an overall mortality rate of about $50 \%$ (Krafft et al., 1996).

\section{Acute Respiratory Distress Syndrome versus Acute Lung Injury}

ARDS is a severe form of acute lung injury (ALI). ALI is defined as a syndrome of inflammation and increased pulmonary capillary permeability associated with a constellation of clinical, radiographic, and physiologic abnormalities not explained by, but possibly coexistent with, left atrial hypertension (Bernard et al., 1994). The distinction between ARDS and ALI is made based on the degree of hypoxemia. In ALI, the $\mathrm{PaO}_{2} / \mathrm{FIO}_{2}$ ratio is 200 to $300 \mathrm{~mm} \mathrm{Hg}$, whereas in ARDS the ratio is less than $200 \mathrm{~mm} \mathrm{Hg}$.

Patients with severe CAP are at risk for ARDS, with a reported incidence of about $12 \%$. Patients with CAP are at further risk for the development of ARDS if the course of their illness is complicated by sepsis, multiple transfusions, aspiration, or prolonged administration of high inspired concentrations of oxygen (Garberetal.,1996). The distinction between overwhelming pneumonia and ARDS can be difficult, particularly when diffuse radiographic infiltrates are present.

\section{Treatment}

Mechanical Ventilation. The goal of treatment for pneumonia complicated by ARDS is the provision of adequate gas exchange and a reversal of the underlying infection. This typically requires intubation and mechanical ventilation. Guidelines for mechanical ventilation of patients with ARDS are summarized in Table 5. Oxygen toxicity and ventilator-induced barotrauma or volutrauma are the main concerns in this patient population. 
TABLE 5. Mechanical Ventilation and Acute Respiratory Distress Syndrome

Maintain $\mathrm{SaO}_{2}$ at $90 \%$
Attempt to minimize $\mathrm{FIO}_{2}$ and limit plateau pressure to $<35 \mathrm{~cm}$
$\mathrm{H}_{2} \mathrm{O}$
Permit hypercapnia if lower tidal volume required to limit
plateau pressure
Titate PEEP empirically for best oxygen delivery at lowest
PAWP and $\mathrm{FIO}_{2}$
Tidal volume between 7 and $10 \mathrm{~mL} / \mathrm{kg}$
If oxygenation and ventilation continue to be a problem consider
paralysis and/or prone positioning

PEEP, postıve end-expiratory pressure; PAWP, positıve arterial wedge pressure

Fluid Management. The role of fluid management in ARDS is somewhat controversial. Pulmonary edema develops at a lower pulmonary capillary hydrostatic pressure as the permeability of the alveolar capillary membrane increases. Therefore, intravascular volume overload should be avoided and careful diuresis may be undertaken to lower pulmonary artery wedge pressure without compromising cardiac output.

Corticosteroids. A pharmacologic means to attenuate the course of ARDS has been the subject of considerable research. The use of high-dose corticosteroids within the first 48 hours of ARDS has produced disappointing results in randomized trials (Bone et al., 1987). However, it appears that selecting patients during the fibroproliferative phase of ARDS (5 to 10 days after onset) for steroid therapy may be an effective strategy. Recent evidence suggests that methylprednisolone, $2 \mathrm{mg} / \mathrm{kg}$ daily followed by a slow taper, may reduce lung injury and improve survival in patients with late ARDS (Meduri et al., 1998).

Prone Positioning. Some patients with refractory hypoxemia from CAP may benefit from prone positioning. The fact that prone positioning can improve $\mathrm{PaO}_{2}$ has been known for many years (Piehl \& Brown, 1976) but only recently has the mechanism of this improvement been determined. $\dot{V} / Q$ distribution in the lung improves mainly as a result of a shift of blood flow away from dependent shunt regions (Pappert et al., 1994). In patients with acute respiratory failure in whom mechanical ven- tilation has been optimized, prone positioning may represent a temporizing measure while the underlying infection is treated. However, whether this maneuver confers an overall survival benefit has not yet been studied.

Nitric Oxide. Nitric oxide (NO) is a highly reactive, endogenously produced molecule with many biological effects. In the lung, NO is a potent vasodilator that helps to maintain low resting pulmonary vascular tone. The administration of inhaled NO to patients with ARDS can result in a significant improvement in oxygenation without apparent adverse hemodynamic or systemic effects (Dellinger et al., 1998; Rossaint et al., 1993). Despite these acute physiologic improvements in patients the usefulness of inhaled NO in altering outcome in patients with ARDS appears doubtful, with two randomized trials showing no survival benefit from the administration of NO (Michael et al., 1998; Troncy et al., 1998).

Exogenous Surfactant. Administration of aerosolized surfactant is the mainstay of treatment for neonatal respiratory distress syndrome. There is evidence that ARDS is a state of both functional and quantitative surfactant deficiency. For these reasons, there is considerable interest in surfactant replacement as a means to improve lung compliance and attenuate alveolar collapse in the ICU. Despite these theoretical benefits, clinical studies examining exogenous surfactant administration have shown mixed results. One large randomized controlled trial by Anzueto et al. (1996) found that aerosolized surfactant failed to confer any significant short- or long-term benefit in patients with ARDS.

\section{Line Sepsis}

Patients in the ICU frequently have central venous and intra-arterial catheters to permit continuous hemodynamic monitoring. Despite the wealth of information these catheters provide, they are not without complications. Bacteremia, often from Staphylococcus spp., (coagulase positive and negative), is a common consequence of invasive monitoring and should be considered whenever unexplained fever, leukocytosis, or persistent systemic inflammatory response syndrome occurs. Routine replacement of indwelling catheters is not war- 


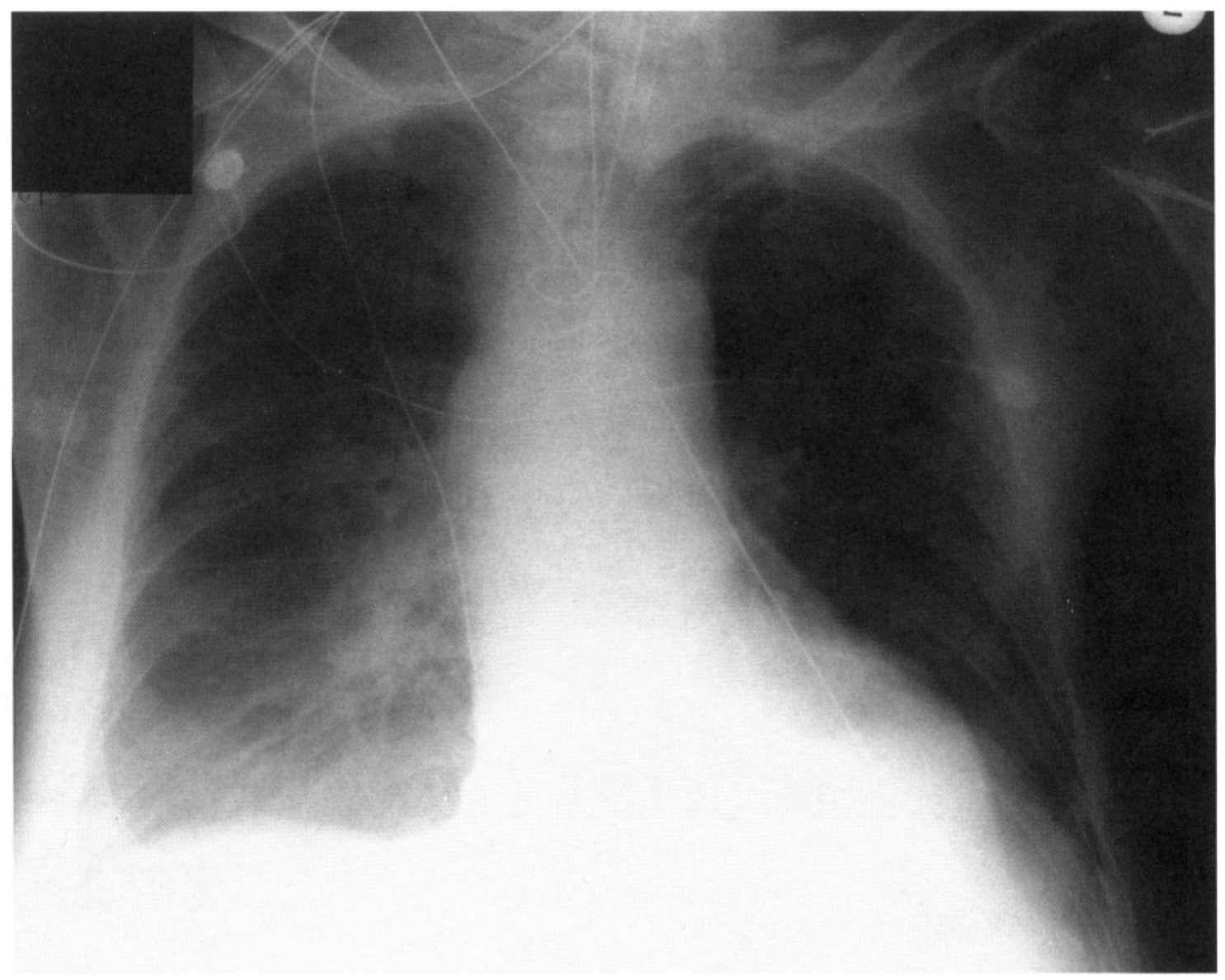

FIGURE 2. (A) Supine portable chest $\mathrm{x}$-ray in a patient admitted to hospital with pneumonia in the apical segment of the right lower lobe. A general increase in density of the right hemithorax was noted as the patient continued to spike fevers despite appropriate antibiotic therapy. (B) A CT scan confirmed the presence of a right-sided parapneumonic effusion. The fluid was cultured and grew Pneumococcus. After chest tube drainage, the patient's fever cleared and he made a full recovery. (Continued)

ranted in the absence of these signs. Nevertheless, the need for such invasive lines should be reviewed daily.

\section{Empyema}

Parapneumonic effusions are frequent complications of severe CAP. Pleural effusions may be difficult to appreciate radiographically, particularly in ICUs where daily chest radiographs are obtained in the supine position. When the patient is supine, the pleural fluid is spread over a greater area and therefore a greater amount of fluid must accumulate before it can be seen. The earliest sign is blunting of the costophrenic angle followed by an increased homogeneous density superimposed over the lung (Ruskin et al., 1987) (Figure 2).

These parapneumonic effusions should be managed in the same way as in patients outside the ICU, with the decision to initiate chest tube drainage based on information obtained from diagnostic thoracentesis. This procedure can be performed safely on patients who are mechanically ventilated. The use of ultrasound to locate the collection of fluid minimizes the likelihood of pneumothorax and is recommended. In a series by McCartney et al. (1993) the incidence of pneumothorax following thoracentesis in mechanically ventilated patients 


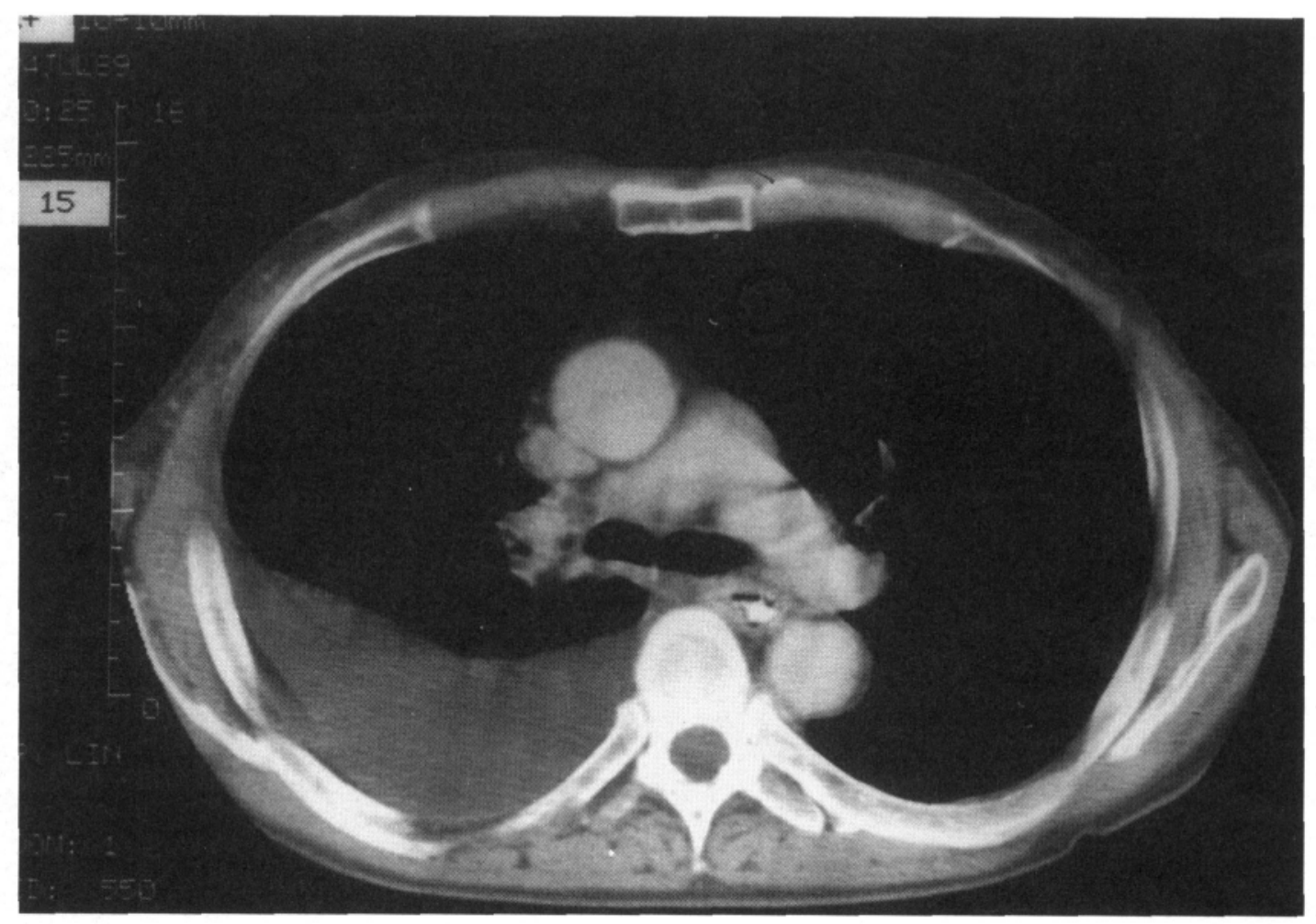

FIGURE 2. (Continued)

was $10 \%$ and these patients were successfully managed with a chest tube.

\section{Prognosis}

The mortality rate for severe CAP is about 25\% (Torres et al., 1991; Leroy et al., 1995). This is similar to death rates seen in patients hospitalized with CAP but not requiring ICU management (Marrie et al., 1989).

Several studies have now examined independent predictors of mortality in severe CAP using multivariate analysis and recursive partitioning (Table 6). Several of these predictors, including a high simplified acute physiologic score and septic shock, simply reflect the severity of the underlying infection and may not be amenable to intervention. Interestingly, Leroy et al. (1996) demonstrated that failure to provide effective initial empiric therapy was an independent predictor of mortality, with a risk ratio of 4.94 .

\section{Summary}

CAP is a common cause of ICU admission and continues to be associated with a significant mortality rate. Several large epidemiologic studies have established the importance of $S$. pneumoniae, $L$. pneumophila, and gram-negative bacilli as major pathogens in severe CAP. The provision of adequate tissue oxygenation with noninvasive or invasive mechanical ventilation, hemodynamic support, aggressive empiric antibiotic therapy, and vigilance for common complications represents the foundation of ICU management of severe pneumonia. 


\section{TABLE 6. Prognosis and Severe CAP}

\begin{tabular}{lcll}
\hline Author & $\begin{array}{c}\text { Number of } \\
\text { patients }\end{array}$ & \multicolumn{1}{c}{ Design } & \multicolumn{1}{c}{ Predictors of mortality } \\
\hline Leroy et al., 1996 & 335 & Retrospective & $\begin{array}{l}\text { SAPS } \geqslant 12 \\
\text { Neutrophils } \leqslant 3500 / \mathrm{mm}^{3} \\
\text { Delayed mechanical ventilation } \\
\text { Immunosuppression } \\
\text { OSF score } \geqslant 2 \\
\text { Ineffective initial antimicrobial therapy } \\
\text { Septic shock }\end{array}$ \\
& 132 & Prospective & $\begin{array}{l}\text { SAPS }>13 \\
\text { Streptococcus pneumonia } \\
\text { Torres et al., 1991 }\end{array}$ \\
& 92 & Prospective & $\begin{array}{l}\text { Enterobacteriaceae } \\
\text { Radiographic spread of pneumonia } \\
\text { Septic shock }\end{array}$ \\
\hline
\end{tabular}

SAPS, Simplified acute physiologic score; OSF, organ system failure.

\section{References}

Antonelli, M., Conti, G., Rocco, M., Bufi, M., De Blasi, R. A., Vivino, G., Gasparetto, A., \& Meduri, G. U. (1998). A comparison of noninvasive positive-pressure ventilation and conventional mechanical ventilation in patients with acute respiratory failure. N. Engl. J. Med., 339, 429-435.

Anzueto, A., Baughaman, R. P., Guntupalli, K. K., Weg, J. G., Wiedemann, H. P., Raventos, A. A., Lemaire, F., Long, W., Zaccardelli, D. S., \& Pattishall, E. N. (1996). Aerosolized surfactant in adults with sepsis-induced acute respiratory distress syndrome. N. Engl. J. Med., 334, 1417-1421.

Bartlett, J. G., Breiman, R. F., Mandell, L. A., \& File, T. M., Jr. (1998). Community-acquired pneumonia in adults: guidelines for management, Clin. Inject. Dis., 26, 811-838.

Bernard, G. R., Luce, J. M., Sprung, C. L., Rinaldo, J. E., Tate, R. M., Sibbald, W. J., Karima, K., Higgins, S., Bradley, R., \& Metz, C. A. (1987). High-dose corticosteroids in patients with the adult respiratory distress syndrome. N. Engl. J. Med., 317, 1565-1570.

Bernard, G. R., Artigas, A., Brigham, K. L., Carlet, J., Falke, K., Hudson, L., Lamy, M., Legall, J. R., Morris, A., \& Spragg, R. (1994). The American-European Consensus Conference on ARDS. Definitions, mechanisms, relevant outcomes, and clinical trial coordination. Am. J. Respir. Crit. Care Med., 149, 818-824.

Dahmash, N. S., \& Chowdhury, M. N. H. (1994). Re-evaluation of pneumonia requiring admission to an intensive care unit: a prospective study. Thorax, 49, 71-76.

Dellinger, R. P., Zimmerman, J. L., Taylor, R. W., Straube, R. C., Hauser, D. L., Criner, G. J., Davis, K., Jr., Hyers, T. M., \& Papadakos, P. (1998). Effects of inhaled nitric oxide in patients with acute respiratory distress syndrome: results of a randomized phase II trial. Inhaled nitric oxide in ARDS Study Group. Crit. Care Med., 26, 15-23.

Ewig, S., Ruiz, M., Mensa, J., Marcos, M. A., Martinez, J. A.,
Arancibia, R, Niederman, M. S., \& Torres, A. (1998). Severe community-acquired pneumonia: assessment of severity criteria. Am. J. Respir. Crit. Care Med., 158, 1102-1108.

File, T. M., Jr., Segreti, J., Dunbar, L., Player, R., Kohler, R., Williams, R. R., Kojak, C., \& Rubin, A. (1997). A multicenter, randomized study comparing the efficacy and safety of intravenous and/or oral levofloxacin versus ceftriaxone and/or cefuroxime axetil in treatment of adults with community-acquired pneumonia. Antimicrob. Agents Chemother., 41, 1965-1972.

Finch, R., Macfarlane, J. T, Selkon, J. D., Watson, J. White, R. J., Winter, J. H., \& Woodhead, M. A. (1993). Guidelines for the management of community-acquired pneumonia in adults admitted to hospital, Br. J. Hosp. Med., 49, 347-350.

Garber, B. G., Herbert, P. C., Yelle, J. D., Hodder, R. V., \& McGowan J. (1996). Adult respiratory distress syndrome: a systemic overview of incidence and risk factors. Crit. Care Med., 24, 687-695.

Hirani, N. A., \& Macfarlane, J. T. (1997). Impact of management guidelines on the outcome of severe community acquired pneumonia. Thorax, 52, 17-21.

Keenan, S. P., Kernerman, P. D., Cook, D. J., Martin, C. M., McCormack, D., \& Sibbald, W. J. (1997). Effect of noninvasive positive pressure ventilation on mortality in patients admitted with acute respiratory failure: a metaanalysis. Crit. Care Med., 25, 1685-1692.

Krafft, P., Fridrich, P., Pernerstorter, T., Fitzgerald, R. D., Koc, D., Schneider, B., Hammerle, A. F., \& Steltzer, H. (1996). The acute respiratory distress syndrome: Definitions, severity and clinical outcome. An analysis of 101 clinical investigations. Intens. Care Med., 22, 519-529.

Lampron, N., Lemaire, F., Teissseire, B., Harf, A., Palot, M., \& Matamis, D. (1985). Mechanical ventilation with $100 \%$ oxygen does not increase intrapulmonary shunt in patients with severe bacterial pneumonia. Am. Rev. Respir. Dis., 131, 409-413. 
Leroy, O., Georges, H., Beuscart, C., Guery, B., Coffinier, C., Vandenbussche, C., Thevenin, D., \& Beaucaire, G. (1996). Severe community-acquired pneumonia in ICUs: prospective validation of a prognostic score. Intens. Care Med., 22, 1307-1314.

Leroy, O., Santre, C., Beuscart, C., Georges, H., Query, B., Jacquier, J. M., \& Beaucaire, G. (1995). A five-year study of severe community-acquired pneumonia with emphasis on prognosis in patients admitted to an intensive care unit. Intenx. Care Med., 21, 24-31.

Levy, H., \& Simpson, S. Q. (1994). Hantavirus pulmonary syndrome. Am. J. Rexpir. Crit. Care Med., 149, 1710-1713.

Marrie, T. J. (1993). Mycoplasma pneumoniae pneumonia requiring hospitalization, with emphasis on infection in the elderly. Arch. Intern. Med., 153, 488-494.

Marrie, T. J., Durant, H.. \& Yates, L. (1989). Communityacquired pneumonia requiring hospitalization: 5-year prospective study. Rev. Infect. Dis., 11, 586-598.

McCartney, J. P., Adams, J. W., \& Hazard, P. B. (1993). Safety of thoracentesis in mechanically ventilated patients. Chest, 103, 1920-1921.

Meduri, Q. U., Headley, S. A., Golden, E., Carson, S. J., Umberger, R. A., Kelso, T., \& Tolley, E. A. (1998). Effect of prolonged methylprednisolone therapy in unresolving acute respiratory distress syndrome. JAMA, 280, 159-165.

Michael, J. R., Barton, R. G., Saffle, J. R., Mone, M., Markewitz, B. A., Hillier, K., Elstad, M. R., Campbell, E. J., Troyer, B. E., Whatley, R. E., Liou, T. G., Samuelson, W. M., Carveth, H. J., Hinson, D. M., Morris, S. E., Davis, B. L., \& Day, R. W. (1998). Inhaled nitric oxide versus conventional therapy. Am. J. Respir. Crit. Care Med., 157, 1372-1380.

Minard, G., \& Kudsk, K. A. (1998). Nutritional support and infection: does the route matter? World J. Surg.,22, 213-219.

Moine, P., Vercken, J. B., Chevret, S., Chastang, C., Gajdos, P., $\&$ the French Study Group for Community-Acquired Pneumonia in the Intensive Care Unit. (1994). Severe communityacquired pneumonia: Etiology, epidemiology, and prognosis factors. Chest, 105, 1487-1495.

Niederman, M. S., Bass, J. B., Jr., Campbell, G. D., Fein, A. M., Grossman, R. F., Mandell, L. A., Marrie, T. J., Sarosi, G. A., Torres, A., \& Yu, V. L. (1993). Guidelines for the initial management of community-acquired pneumonia: diagnosis, assessment of severity, and initial antimicrobial therapy. Am. Rev. Respir. Dis., 148, 1418-1426.

Pachon, J., Prados, M. D., Capote, F., Cuello, J. A., Garnacho, J., \& Verano, A. (1990). Severe community-acquired pneumonia: etiology, prognosis, and treatment. Am. Rev. Respir. Dis., 142, 369-373.

Pallares, R., Linares, J., Vadillo, M., Cabellos, C., Manresa, F., Viladrich, P. F, Martin, R., \& Gudiol, F. (1995). Resistance to penicillin and cephalosporin and mortality from severe pneumococcal pneumonia in Barcelona, Spain. N. Engl. J. Med., 333, 474-480.

Pappert, D., Rossaint, R., Slama, K. Gruning, T, \& Falke, K. J. (1994). Influence of repositioning on ventilation-perfusion relationships in severe adult respiratory distress syndrome. Chest, 106, 1511-1516.

Piehl, M. A., \& Brown, R. S. (1976). Use of extreme position changes in acute respiratory failure. Crit. Care Med., 4, 13-15.

Plouffe, J. F., Breiman, R. F., \& Facklam, R. R. (1996). Bacteremia with Streptococcus pneumoniae. JAMA, 275, 194-198.

Rello, J., Quintana, E., Ausina V., Net, A., \& Prats G. (1993). A three-year study of severe community-acquired pneumonia with emphasis on outcome. Chest, 103, 232-235.

Rello, J., Rodriguez, R., Jubert, P., Alvarez, B., \& the Study Group for Severe Community-Acquired Pneumonia. (1996). Severe community-acquired pneumonia in the elderly: epidemiology and prognosis. Clin. Infect. Dis., 23, 723-728.

Rossaint, R., Falke, K. J., Lopez, F. A.. Slama, K., Pison, U., \& Zapol, W. M. (1993). Inhaled nitric oxide for the adult respiratory distress syndrome. N. Engl. J. Med., 328, $399-405$.

Ruskin, J. A., Gurney, J. W., Thorsen, M. K., \& Goodman, L. R. (1987). Detection of pleural effusions on supine chest radiographs. Am. J. Roentgenol, 148, 681-683.

Sorensen, J. A., Forsberg, P., Hakanson, E.. Mailer, R., Sederholm, C., Soren, L., \& Carlsson, C. (1989). A new diagnostic approach to the patient with severe pneumonia. Scantt. J. Infect. Dis., 21, 33-41.

Stout, J. E., \& Yu, V. L. (1997). Legionellosis. N. Engl. J. Med., 337, 682-687.

Tan, Y. K., Khoo, K. L., Chin, S. P., \& Ong, Y. Y. (1998). Aetiology and outcome of severe community-acquired pneumonia in Singapore. Eur. Respir. J., 12, 113-115.

Torres, A., Serra-Batlles, J., Ferrer, A., Jimenez, P., Celis, R., Cobo, E., \& Rodriguez-Roisin, R. (1991). Severe communityacquired pneumonia: epidemiology and prognostic factors. Am. Rev. Respir. Dis., 144, 312-318.

Troncy, E., Collet, J., Shapiro, S., Guilmond, J., Blair, L., Ducruet, T., Francoeur, M., Charbonneau, M., \& Blaise, G. (1998). Am. J. Respir. Crit. Care Med., 157, 1483-1488.

Valenti, M. V., Trudell, R. G., \& Bentley, D. W. (1978). Factors predisposing to oropharyngeal colonization with gramnegative bacilli in the aged. N. Engl. J. Med., 298, 11081111.

Woodhead, M. A., Macfarlane, J. T., Rodgers, F. G., Laverick A., Pilkington, R., \& Macrae, A. D. (1985). Aetiology and outcome of severe community-acquired pneumonia. J. Infect., $10,204-210$. 